\title{
A LANÇA E O ARCO, OU POR UM DEVIR-QUILOMBISTA DA ARTE $^{1}$
}

THE LANCE AND THE ARC, OR FOR A QUILOMBIST-BECOMING OFART

\section{Jorge Vasconcellos}

UFF

Resumo: Afirmamos que há em curso um giro minoritário da arte contemporânea, a partir do qual defendemos que é possível pensar que, em certas práticas artísticas caracterizadas por nós como contra-arte, articula-se um devir-quilombista realizado por artistas-ativistas negrxs-indígenas. Este devir-quilombista é autodefesa e contra-ataque, por intermédio de ações de guerrilha artística, do Povo Preto brasileiro.

Palavras-Chave: giro minoritário, devir-quilombista, arte e contra-arte, arte contemporânea.

Abstract: We affirm that there is an ongoing minority tour of contemporary art, from which we argue that it is possible to think that, in certain artistic practices characterized by us as counter-art, a becoming-quilombist articulated by black-indigenous artist-activists. This becoming-quilombista is self-defense and counterattack, through artistic guerrilla actions, of the Brazilian Black People.

Keywords: minority tour, becoming-quilombista, art and counter-art, contemporary art.

1 Texto a partir de uma fala-intervenção realizada a convite da Coletiva de Arte Afro-indígena Ateliê Terreiro, por intermédio da artista Luanda Francisco, no dia 20 de novembro de 2020, Dia da Consciência Negra, no Evento "21 Dias Contra o Racismo". Para assistir, Canal YouTube Ateliê Terreiro: https://youtu.be/NCnNJRgSJWE 


\section{Boa Saúde à toda-o-es!}

Neste dia há justos 325 anos, em um 20 de novembro de 1695, Zumbi era traído por um dos seus, emboscado, assassinado e decapitado por Domingos Jorge Velho... e Palmares caía. Entretanto, seu legado e de todxs xs quilombolas palmerinxs permanece conosco em ideia e força, articulando o que é aqui chamado de Quilombismo.

O Quilombismo não é apenas um momento histórico do Brasil ou mesmo uma ideia que se perdeu... Trata-se, antes disso, de uma força motriz do Povo Preto (negrxs/indígenas) brasileiro. Foi e é contrapoder ao processo encarcerador dxs negrxs escravizadxs nas Américas, fruto da diáspora atlântica forçada pelo colonialismo, especialmente dos séculos XVII e XVIII. E campo de lutas ao extermínio necropolítico de negrxs e indígenas. O Quilombismo é pensamento negro-brasileiro nas obras de Abdias Nascimento, de Beatriz Nascimento, de Lélia Gonzales, do Mestre Nêgo Bispo e, também, abertura possível ao pensamento de Ailton Krenak e de Davi Kopenawa. Mas, também, é possível ser pensado e atualizado em processos e linhas de força que chamaremos de devires. Estes devires são aquilombamentos e aldeamenteos em lugar/ sítio e espaço/tempo, em ações e práticas estético-políticas, sejam elas nos ativismos contemporâneos (o feminismo negro/as lutas indígenas de nossa atualidade), ou, na arte contemporânea (nas artes visuais, nas ações performáticas, no cinema de guerrilha, nas literaturas insurgentes). O Quilombismo é, em nossa perspectiva, um devir-quilombista. Falaremos e clamaremos nesta intervenção Por um devir-quilombista da arte. Justamente, neste devir-quilombista da arte, negrxs-indígenas/indígenas/ negrxs, tomam de assalto à casa grande da arte contemporânea, produzindo aquilombamentos e aldeamentos das galerias/feiras/bienais do mercado capitalista neo-liberal das artes... e não só! Isso porque esse devir-quilombista é crítica e é clínica aos poderes instituídos, já que se apresenta duplamente: como forma de contrapoder; e, como produção de acolhimento e invenção de modos de outros de práticas artísticas e existências a partir de procedimentos coletivos, comunitários, colaborativos... àquelxs que se deixem atravessar por esses devires. "O devir-quilombista da arte é manual (aberto) de autodefesa do Povo Preto ao campo das artes".

Diante de tantas ações e práticas de extermínio do Povo do Preto brasileiro, sejam pessoas negras e/ou indígenas precisamos urgir em nossa autodefesa e contra-ataque a lança de Zumbi e fazer vergar o arco, endereçando a flecha Xavante para, mais do que dizer um "basta!" a tudo isso... precisamos, também, justamente, ir às ruas para se autodefender e contra-atacar ao ataque dos exterminadores de nosso futuro -passado-presente que impetram um genocídio a céu aberto sobre nós. Contudo, esta autodefesa e contra-ataque que endereça a lança negra e a flecha indígena é uma espécie de arquivo-arma (memória-ferramenta) das poderosidades do Povo Preto brasileiro. Até porque essas armas que estamos clamando, não se trata de armas esculpidas da madeira da floresta ou forjadas em quaisquer metais. Tratam-se, isto sim, de táticas de luta políticas minoritárias, sob a forma de guerrilhas artísticas no campo de forças que compreende a arte contemporânea, e alhures.

Dito isto, partamos para a conversa que aqui teremos. Parto de uma proposição, ou mais precisamente de uma inflexão, para este "chamado" por nós designado de um devir-quilombista da arte. Esta inflexão e sentido a qual denominamos de "giro minoritário na arte contemporânea”. Mostrar que hoje eclode no seio do sistema de arte, desde os recortes curatoriais, a construção de nova fortuna crítica, a presença 
em feiras e galerias de negócios, na construção e aquisição de acervos, sejam eles públicos ou privados e, ainda, na presença dessa perspectiva e lutas minoritárias em bienais (Bienal de São Paulo, por exemplo) e quinquienais de arte (Documenta de Kassel, por exemplo)... destacamos, fortemente, a presença de artista de recortes étnico-raciais negro-indígenas ou indígenanegros que representam a partir de suas obras, objetos, ações e práticas as questões de registro minoritário, as lutas do movimento e/ou do feminismo negro e as lutas dos povos indígenas. E mais, esses processos de representatividade no sistema da arte contemporânea não estão apenas relacionados às questões étnico-raciais, mas também às questões de gênero, como, por exemplo, dos feminismos (particularmente do feminismo negro) e das lutas das travestis e das pessoas transvestigenere. Nos perguntamos, então, o que é, de fato este giro minoritário da arte contemporânea?

Em primeiro lugar, a posição que defendemos acerca do "giro" (minoritário da arte contemporânea) diz respeito aos seus próprios termos. 0 século XX, notadamente a partir de uma leitura que se paute por uma história dos sistemas de pensamento, se viu implicado pelo que foi chamado de uma dupla virada. A primeira dessas viradas ficou conhecida como "virada linguística”, a qual defende que os saberes humanos, em especial a filosofia, deferia ter como foco de investigação privilegiadamente os estudos sobre a linguagem. Pensadores da linguagem como Ludwig Wittgenstein e Bertrand Russel e seus legados filosóficos foram decisivos para o que foi designado por uma certa filosofia anglo-saxão de "linguistic turn", virada linguística, ou mesmo giro linguístico. À esta virada/giro autoproclamado de "linguístico" ocorre, como reação, o que acabou por ser denominado de "virada antropológica da filosofia", que pregava não propriamente o abandono às questões ligadas ao campo da linguagem, mas subordiná-las às referências do sujeito e da história e retomar as questões de orientação onto-políticas. De nossa parte, nos apropriamos aqui do sentido de giro/virada para designar um momento de eclosão das lutas minoritárias no campo das artes, privilegiadamente o campo expandido das artes visuais. Então, o sentido de virada, ou exatamente como chamamos de giro, é o de mudar o foco e o enfoque dos estudos de uma determinada área de pensamento e atuação, mas também, a construção de uma de campo de diagnóstico do presente que dê conta das regularidades de certas práticas sociais, no caso a Arte e seus novos atores, questões, abordagens e agenciamentos de enunciação que estão reorientando seu próprio sistema.

Em segundo lugar, a posição que defendemos acerca do "giro" (minoritário da arte contemporânea) é que se deu/está se dando, como dissemos, uma virada, uma mudança de rumo. Dito outro modo: afirmamos, como hipótese, que há em curso uma mudança de sentido na rota que leva ao Lugar da arte contemporânea de seu mercado e ao sistema na Atualidade, sistema este que consideramos é dominado por dispositivos biopolíticos de racialização. Dispositivos estes calcados no colonialismo e em suas várias formas de racismo, orientados pelo que o chamado pelo ativismo preto denomina de "branquitude" e que nós, seguindo a filósofa Denise Ferreira da Silva, nomeamos de "branquidade". Defendemos que a arte contemporânea está (e muito precisa-estar) se empretecendo. Evidentemente, não estamos afirmando que arte se tornou negra-indígena, ou mesmo, que hoje encontramos nas mostras, bienais, feiras, etc, uma maioria de artistas negrxs-indígenas. Ao contrário, o que temos o é justamente o oposto, isto é, uma maioria esmagadora de artistas 
não-Pretos (negrx-indígenas) nesses Lugares da arte. Contudo, o que aqui defendemos como análise e diagnóstico de um tempo que se faz cada vez mais presente é, justamente, esta mudança incontornável de rumo e sentido: a força que potencializa a arte da contemporânea hoje é (deve ser: devir) negra-indígena. Dizemos com veemência: a lança negra e a flecha indígena estão endereçadas a um futuro que já é, necessariamente, nosso presente, relendo nosso passado e contracolonialmente transmutando-o em um outro porvir. Por isso também afirmamos: toda a ira antirracista que leva o Povo Preto às armas da guerrilha artística é sagrada.

A arte preta contemporânea brasileira é o sopro de renovação dos estados das artes em nossa Atualidade.

E por quê? Aqui temos o terceiro ponto de nossa argumentação.

Em terceiro lugar, a posição que defendemos acerca deste "giro" (minoritário da arte contemporânea) é que este pode ser pensado como uma forma de luta política, de luta de minorias, de luta minoritária. Nessas lutas há como que uma indiscernibilidade entre ser um/uma/ume artista e ser um/uma/ume ativista à qual seu estado de ser comporta. Ser negro/negra/negre ou ser indígena, apenas para ficar no Povo Preto, mas poderíamos falar das trans, das travas, das transvestigeneres. Trata-se de tornar mais que poroso esta relação entre artista e ativista. Trata-se de mostra e fazer ver que não há distinção possível entre o/a ativista e o/a ativista. Não se trata mais de obra ou processo artístico, mas de ações e práticas artísticas-ativistas que são, sempre, enfrentamentos aos poderes instituídos que podem, por vezes, inadvertidamente produzir uma zona cinzenta entre a arte e o crime. Isto sem nunca deixar de ser, de fato, ações e práticas legítimas e justas à causa que estes e estas artistas-ativistas defendem com suas ações e práticas no campo das artes, melhor dizendo, no campo social que agem e militam.

O giro minoritário da arte contemporânea engendra, nessa perspectiva, um devir-quilombista das artes:

Abdias Nascimento e

Arjan Martins,

Ayrson Heráclito,

Castiel Vitorino,

Daiara Tukano,

Dalton Paula,

Daniel Lima,

Denilson Baniwa,

Elian Almeida,

Elton Sara Panamby,

Frente 3 de Fevereiro,

Jaider Esbell Makuxi,

Jaime Lauriano,

Jota Mombaça,

Marcelo D'Salete,

Maré de Matos,

Maxwell Alexandre,

Mulambo,

Moara Brasil Pankararu,

Musa Mattiuzzi,

Naine Terena,

Olinda Yawar Tupinanbá,

Panmela Castro,

Paulo Nazarath,

Renata Felinto,

Rosana Paulino,

Sidney Amaral,

Sonia Gomes,

Tiago Sant'Ana,

Xadalu Tupã Jekupé e

Yhuri Cruz...

1+30 nomes de artistas-ativistas às lutas minoritárias de nosso tempo presente. De Abdias Nascimento... o "A" do Arco e da lançA que inaugura, não como primeiro, mas como ponto de partida, ao que denominamos de devir-quilom- 
bista da arte... à Yhuri Cruz, jovem e poderoso artista negro carioca, passando por Arjan Martins, Ayrson Heráclito, Castiel Vitorino, Daiara Tukano, Dalton Paula, Daniel Lima, Denilson Baniwa, Elian Almeida, Elton Sara Panamby, Frente 3 de Fevereiro, Jaider Esbell Makuxi, Jaime Lauriano, Jota Mombaça, Marcelo D’Salete, Maré de Matos, Maxwell Alexandre, Mulambo,Moara Brasil Pankararu, Musa Mattiuzzi, Naine Terena, Olinda Yawar Tupinanbá, Panmela Castro, Paulo Nazarath, Renata Felinto, Rosana Paulino, Sidney Amaral, Sonia Gomes, Tiago Sant'Ana e Xadalu Tupã Jekupé... todas, todos e todes que apontam a Lança e vergam o Arco do pioneiro Abdias e mais além...

\section{Referências}

28 de Maio, Coletivo. VASCONCELLOS, Jorge e PIMENTEL, Mariana. "O que é uma ação estético -política? (um contramanifesto)". Revista Vazantes, periódico do Programa de Pós-graduação em Artes da Universidade Federal do Ceará/ PPGArtes-UFC, $n^{\circ}$ 1. pp. 192-200

BASBAUM, Ricardo. Manuel do artista-etc. Rio de Janeiro: Beco do Azougue, 2013.

BEY, Hakim. TAZ - Zona Autônoma Temporária. São Paulo: Conrad Editora do Brasil, 2011.

___. Caos, terrorismo poético e outros crimes exemplares. (Web)

CAMNITZER, Luis. "Arte contemporânea colonial". Escritos de artistas: anos 60/70. FERREIRA, Glória e COTRIM, Cecília (orgs.). Rio de Janeiro: Jorge Zahar Editor, 2009, 266-274.

DELEUZE, Gilles. Conversações. São Paulo: Editora 34, 1992.

FERREIRA DA SILVA, Denise. A dívida impagável. Lendo cenas de valor contra a flecha do tempo. São Paulo Edições Casa do Povo, 2017.

FOUCAULT, Michel. Microfísica do Poder. Rio de Janeiro: Graal, $3^{a}$ edição, 1982.

GONZALEZ, Lélia. Primavera para as rosas negras. Diáspora Africa: Editora Filhos da África, 2018.

GUATTARI, Félix. Revolução Molecular: pulsações políticas do desejo. São Paulo: Brasiliense, $2^{a}$ edição, 1985.

GUÉRON, Rodrigo e VASCONCELLOS, Jorge. "depois de junho... o que nos resta fazer? ações estético-políticas! (notícia de um Brasil insurgente: as manifestações de junho-2013 e a reação microfascista a elas)". Ouro Preto-MG: Revista ALEGRAR, n 15, 2015.

MORAIS, Frederico. "Contra a arte afluente: o corpo é o motor da "obra". Ensaios Fundamentais: Artes plásticas. COHEN, Sérgio (org.). Rio de Janeiro: Azougue Editorial, 2010, 123-131.

NASCIMENTO, Abdias. O Quilombismo - documentos de uma militância Pan-Africanista. $3^{a}$ edição. São Paulo: Editora Perspectiva, 2019.

NASCIMENTO, Beatriz. Possibilidade nos dias de destruição. Diáspora Africana: Editora Filhos da África, 2018.

NÊGO BISPO (Antônio Bispo dos Santos). CoIonização, Quilombos: modos e significação. Brasília: Instituto de Inclusão no Ensino Médio. UnB, 2015.

KOPENAWA, Davi e ALBERT, Bruce. A queda do céu. Palavras de um Xamã Yanomami. São Paulo: Cia das Letras, 2015.

KRENAK, Ailton. Ideias para adiar o fim do mundo. São Paulo: Cia. das Letras, 2019.

PIMENTEL, Mariana. "A obra de arte na era de sua reprodutibilidade estética ou JR." In: ANPAP, 2011, Rio de Janeiro. Anais do Encontro Nacional da ANPAP (Cd-Rom), 2011.

PIMENTEL, Mariana. "Fabulemos! Ou como resistir à ficção". Conexões: Deleuze e Política e Resistências e... GALO, Silvio et alii (org). Petrópolis: Editora De Petrus, 2013, pp. 173-185.

PRECIADO, Paul B. Um apartamento em Urano - Crônicas da travessia. Rio de Janeiro: Editora Zahar, 2019. 
RAMIREZ, Mari Carmen. "Táticas para viver da adversidade. Conceitualismo na América Latina". Arte \& Ensaios, Revista do PPGAV-EBA-UFRJ, $n^{\circ} .15,2007$.

VASCONCELLOS, Jorge e CASTELO BRANCO, Guilherme. Arte, Vida e Política: ensaios sobre Foucault e Deleuze. Rio de Janeiro: Edições LCV/ SR3?UERJ, 2010.

VASCONCELLOS, Jorge. "A anarquitetura de Gordon Matta-Clark: autonomismo político e ativismo estético". Arte \& Ensaios. Revista do PPGAV-EBA-UFRJ, nº. 25, maio 2013, pp. 88-99.

VASCONCELLOS, Jorge e ROCHA, Isabelle. "Práticas artísticas na rua e ativismo político: entre fronteiras e continuidades". IN: A cidade em obras: imaginar, ocupar, redesenhar. Publicação do Centro Municipal de Artes Hélio Oiticica. PUCU, Izabela Pucu et alii (org.). Rio, 2015, pp. 66-73.

\section{Jorge Vasconcellos}

Negro-indígena. Doutor em Filosofia. Professor do Associado na Universidade Federal Fluminense/UFF, Niterói-RJ/Brasil, no Departamento de Artes e Estudos Culturais/RAE e no Programa de Pós-graduação em Estudos Contemporâneos das Artes/PPGCA. É o atual Coordenador do Programa/PPGCA-UFF (2019-2023). Líder do Grupo de Pesquisas CNPq - práticas estético-políticas na arte contemporânea. Teórico-ativista no Coletivo de ações e práticas estéticos-políticas e procedimentos acadêmicos contrapedagógicos 28 de Maio. Cientista de Nosso Estado/CNE-2020 pela FAPERJ. Fez Pós-doutorado em Artes no Instituto de Artes da UERJ (2019). Publicou livros sobre Deleuze, Foucault e Arte Contemporânea, além de ensaios sobre teoria da arte e do cinema em uma perspectiva filosófica. Tem no prelo, Editora Circuito/Edições PPGCA, o Livro da Coleção Mosaico/PPGCA - Coletivo 28 de Maio: arte e lutas minoritárias, com Mariana Pimentel/IART-UERJ. Pai de Valentina/Théo, Joaquim e Zoé. 